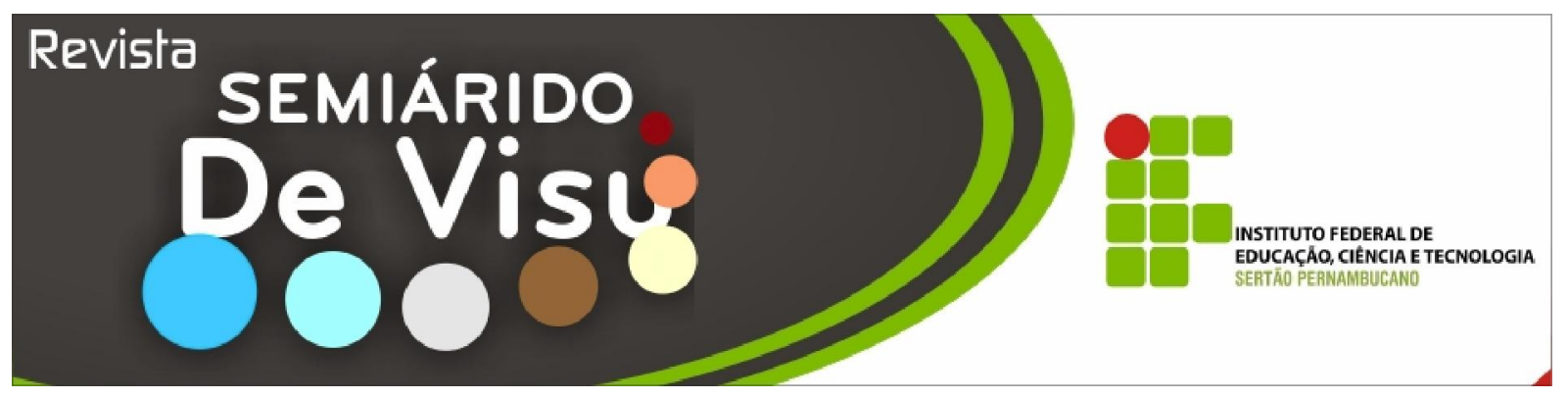

\title{
Projeto interdisciplinar de olerícolas sob cultivo orgânico: sustentabilidade e proficiência escrita
}

\author{
Edilaine Pereira de Sousa ${ }^{1}$, Marcelo de C. Santos Pereira ${ }^{1}$, Antonise Coelho de Aquino ${ }^{1}$, Marcos \\ Vitor do Carmo Loiola ${ }^{1}$, José Batista da Gama ${ }^{1}$, Maria Imaculada da Conceição ${ }^{2}$ \\ ${ }^{1}$ Docentes do IF - Sertão Pernambucano, End.: Rodovia BR 235 Km 22 Projeto Senador Nilo Coelho N4, Petrolina-PE \\ CEP: 56.300-000 - Fone: (87) 3862-3800, e-mail: laninhapsousa1@,hotmail.com, marcelo1agro@hotmail.com, \\ antonisecoelho@hotmail.com, mloiola@gmail.com,jose.gama@ig.com.br. \\ ${ }^{2}$ Estudante (bolsista do PIBIC Jr.), e-mail: imaculadadocinho@hotmail.com
}

RESUMO: A elaboração de projetos na graduação é uma etapa imprescindível. Ao desenvolvê-lo, definem-se objetivos e metas de uma determinada pesquisa. A implantação de olerícola em horta comunitárias com cultivo orgânico pressupõe a execução de um projeto interdisciplinar eficaz. O objetivo deste trabalho foi instalar, com os alunos da turma do I período de Fruticultura Irrigada, uma horta orgânica comunitária no Colégio Municipal do assentamento Água Viva I. Desenvolveu-se a pesquisa qualitativa. Utilizou-se o método indutivo. Fez-se estudo de caso. A partir da problemática da ineficiência de interpretação e produção textual dos discentes, produziram-se mini-projetos. Na análise dos textos, foram utilizados fatores de textualidade, percebeu-se um avanço considerável na escrita dos discentes. A relevância do tema propiciou aos estudantes aplicar os conhecimentos adquiridos em sala. Cabe as Instituições de Ensino primar para que o nível de letramento seja ampliado. Das sementes implantadas, germinaram 100\%.

Palavras-chave: Horta comunitária, Pesquisa, Interdisciplinaridade, Produção Textual.

\section{An interdisciplinary Project of organic olericultural production: sustainability and writing proficiency}

\begin{abstract}
S: The elaboration of projects in the undergraduation course is an indispensable phase. When developing them, researching objectives have to be determined. The implementation of communal gardens with the organic cultivation presumes the elaboration of an efficient interdisciplinary project. The objective of this study was to install a communal organic garden in the municipal college of Agua Viva I settlement, with the participation of the Irrigated Horticulture first-year students. A qualitative research was developed by inductive method and case study. The students' inefficiency in reading and writing skills motivated the formation of mini-projects. Using textual factors, it was perceived a considerable advance in the students' written skills. The relevance of the theme provided the application of the acquired knowledge learned in the classroom. Educational institutions must strive to increase the level of literacy.
\end{abstract}

Keywords: Community Garden, Research, Interdisciplinary, Text Production. 
Edilaine Pereira de Sousa et al.

\section{Introdução}

sustentabilidade é um tema que
desperta crescente interesse e
tem sido destaque em livros, revistas, jornais, fóruns nacionais $\mathrm{e}$ internacionais, uma vez que representa uma das formas de minimizar os impactos ambientais causados pelo mau uso do solo. Devido a isso, há uma necessidade de novas descobertas científicas que considerem a diversidade biológica e sociocultural. E isso pressupõe o desenvolvimento de pesquisas sobre este enfoque.

Durante o primeiro semestre de 2010, surgiu a oportunidade de elaborar um projeto sobre os eixos temáticos: sustentabilidade e agricultura orgânica da turma FI 09 de Fruticultura irrigada do IF - Sertão Pernambucano. Durante a execução, os alunos que apresentaram dificuldade em interpretar e produzir diversos textos (técnicos, científicos, midiáticos) com proficiência. Dos 40 alunos matriculados, $75 \%$ ficaram abaixo da média em Português, devido à ineficiência na interpretação e produção de textos acadêmicos.

Ao adentrar na graduação, os estudantes analisam teoricamente tipos de textos mais ligados a trabalhos de pesquisa (MEDEIROS, 2009). Entretanto, mais que estudar a forma destes textos, era preciso apropriar-se dos gêneros textuais. Segundo Bakhtin (2002) o domínio da cultura letrada envolve a utilização de gêneros discursivos. Considerando que o processo de aprendizagem se estabelece de forma contínua, mediada e autônoma (FEUERSTEIN, 2002), com a elaboração de projetos acadêmicos, os discentes aprenderam a trabalhar em equipe e refletir sistematicamente sobre a realidade empírica.

O pensar interdisciplinar pressupõe uma forma de conhecimento não exaustiva, mas dialogada com outras fontes do saber. Para Fazenda (2002) "a sala de aula deve-se constituir em local de pesquisa". Para esta autora, é uma questão atinente que as Instituições de Ensino precisam superar. O que se designa, pois por interdisciplinaridade é uma atitude epistemológica que ultrapassa os hábitos intelectuais estabelecidos (desenvolver pesquisas apenas de modo isolado) ou mesmo o programa constituído da matriz curricular, que é quase sempre fragmentado. Nesse sentido, a implantação de hortas comunitárias com cultivo orgânico pressupõe um projeto interdisciplinar eficaz que possibilite à prática de conteúdos que serão vivenciados no decorrer do curso pelos graduandos. Definem-se pesquisas interdisciplinares como a busca da construção coletiva de um conhecimento novo. Desse modo, será preciso adequar os saberes prévios dos estudantes com a teoria prevista na ementa do curso e incentivar a prática desses assuntos dentro e fora da sala de aula.

O enfoque da Agricultura Orgânica para promoção da sustentabilidade se dá por diversos fatores, dentre eles a saúde da população versus a má alimentação, sobretudo pela ingestão de produtos com alto teor de agroquímicos. Apesar do conceito de agricultura orgânica ter surgido desde 1925 com o inglês Albert Howard que ressaltava a importância da utilização da matéria orgânica e da manutenção da vida biológica do solo, só a partir dos anos 60, começam a surgir indícios de que a agricultura convencional apresentava sérios problemas energéticos e econômicos e causava um crescente dano ambiental. $\mathrm{Na}$ década de 80 , o movimento cresceu e na de 90 deflagrou. Mesmo assim, a falta de informação, conscientização e fatores socioeconômicos ainda são determinantes para o brasileiro ser um dos que mais exportam e um dos que menos consomem produtos saudáveis e de cultivo orgânico. São exportados em torno de $75 \%$ da produção nacional de orgânicos produzidos no país, principalmente para a Europa, Estados Unidos e Japão.

Mediante o exposto, o objetivo deste trabalho foi desenvolver durante os próximos semestres um projeto interdisciplinar de extensão rural com professores, alunos da turma FI09 e participação da turma 1138 do IF - Zona Rural, visando à preservação ambiental e a sustentabilidade dos agroecossistemas a partir da instalação de uma horta orgânica comunitária no Colégio Municipal do assentamento Água Viva I em Petrolina-PE.

\section{Revisão da literatura}


Edilaine Pereira de Sousa et al.

"O projeto interdisciplinar preconiza estimular vivências que poderão nortear as relações, extirpando mitos, preconceitos e conscientizando para assumir uma postura responsável frente aos desafios que temos de minimizar os impactos causados pela atual mutilação biológica dos ecossistemas". (GUIMARÃES, 2007). A separação entre o ser humano e a natureza para Guimarães (2007) reflete-se em toda a produção humana. A fragmentação do saber, representado pela especialização do conhecimento, aprofundou a compreensão das partes. Contudo, o ambiente é uma unidade que precisa ser compreendida inteira, e é por meio de um conhecimento interdisciplinar que se pode assimilar plenamente o equilíbrio dinâmico.

A educação ambiental deve capacitar ao pleno exercício da cidadania permitindo a formação de uma base conceitual suficientemente diversificada técnica e cultural de modo a permitir que sejam superados os obstáculos à utilização sustentável do meio. Mas é preciso formar pessoas conscientes, críticas, éticas, preparadas para enfrentar esse novo paradigma. A educação ambiental nos níveis formais e informais tem procurado desempenhar esse difícil papel, resgatando valores como o respeito à vida e à natureza, de forma a tornar a sociedade mais justa (PELICIONI, 2000). O estudo desta temática não é de interesse somente de Ambientalistas, Biólogos ou Engenheiros Agrônomos. Por meio de um projeto interdisciplinar eficiente envolvendo sujeitos distintos: família, Instituições de Ensino, comunidade, pode-se desenvolver um trabalho participativo $\mathrm{e}$ contínuo de sustentabilidade e concomitante preservação ambiental.

A busca por pesquisas que enfocam a utilização de produtos naturais está cada vez maior tanto no Brasil como no mundo, pois as altas produtividades obtidas com o uso intensivo de capital, de fertilizantes inorgânicos e de agrotóxicos tem sido questionadas não só por suas contradições econômicas e ecológicas, mas também por desprezar aspectos qualitativos importantes da produção vegetal (SANTOS 2001).

A ampla utilização de agroquímicos no sistema produtivo rural é outro grave problema para a saúde e para o ambiente, por contaminação do solo, da água e do ar (RAMOS, 2009). A produção de alimentos sem o uso de agrotóxicos atua no controle do desequilíbrio ambiental, como a erosão do solo e a poluição das águas. Nesse sentido, define-se Consumo Responsável como a capacidade de cada pessoa ou instituição, pública ou privada, escolher e/ou produzir serviços e produtos que contribuam, de forma ética para a melhoria de vida da sociedade e do ambiente (BARCIOTTE, 2002). "O desenvolvimento da super produção por uma agricultura industrial apresenta grande dificuldade de manter a qualidade ambiental, os recursos naturais, a segurança alimentar e a qualidade de vida rural". (ANDRADE, 2003). Devido à degradação ambiental, renovou-se um interesse pela agricultura sustentável que se configura como o conjunto de princípios e técnicas que visam reduzir a dependência de energia externa e o impacto ambiental da atividade agrícola, produzindo alimentos mais saudáveis e valorizando o homem do campo, sua família, trabalho e cultura (SANTOS 2001). A agricultura sustentável, produtiva e ambientalmente equilibrada apóia-se em práticas conservacionistas de preparo do solo, rotações de culturas e consórcios, no uso da adubação verde, bem como no emprego eficiente dos recursos naturais (ESPINDOLA, 2006).

A produção orgânica, juntamente com o consumo responsável vem como alternativa para a busca de um equilíbrio socioambiental. (FILGUEIRA, 2007). O mercado consumidor tem exigido produtos ecologicamente corretos, desafiando produtores e pesquisadores a promover soluções e adotar práticas agrícolas corretas do ponto de vista ambiental (OLIVEIRA, 2004). Os alimentos orgânicos apresentam um melhor sabor, uma composição mais diversificada em minerais, proporciona nutrição ideal ao corpo humano. Além disso, apresenta maiores teores de carboidratos e matéria seca, além de beneficiar a saúde dos consumidores (FRANCE, 2007). A agricultura orgânica é utilizada para indicar manejos não utilizados na agricultura convencional, pois 
Edilaine Pereira de Sousa et al.

favorecem o equilíbrio entre o ambiente e a produção (ARBOS, 2009).

Segundo Xavier (2006) para manter a produtividade dos solos deve-se considerar a matéria orgânica do solo como a principal fonte de energia e nutrientes do sistema. A utilização de compostos orgânicos, biofertilizantes, ganha cada vez mais importância sob o ponto de vista econômico da conservação das propriedades físicas e químicas do solo e redução do uso de adubos químicos (SOUZA, 1998). De acordo com Souza (2005) o aumento da produtividade por utilização intensa de agrotóxicos, em curto prazo traz resultados econômicos visíveis, podendo contribuir para a diminuição da migração rural e melhoria da distribuição de renda. Ao longo prazo essa forma de cultivo traz danos ambientais irreparáveis para o solo. Nesse sentido, a sustentabilidade é mais importante que a produtividade exacerbada e inadequada. Produzir de modo correto pressupõe o solo fértil por mais tempo, a rentabilidade pouco menos comprometida e qualidade de vida da população.

Por outro lado, com a produção de gêneros textuais específicos como projeto, é possível perceber o avanço considerável na escrita dos discentes. Utilizando o fator da situacionalidade, a produção torna-se relevante para a situação comunicativa (KOCH, 2006). A prática de reescrituração de textos possibilita corrigir os desvios gramaticais bem presentes nas produções e na estrutura textual dos alunos. (DELL'ISOLA, 2007). Além disso, a revisão de gramática prevista na ementa com os seguintes conteúdos: (pontuação, acentuação, regência, concordância e outros) poderão ser vistos em Português de forma contextualizada conforme preconizam os PCNs Parâmetros Curriculares Nacionais, a gramática aplicada ou funcional, inserida em uma situação concreta de uso de algum gênero textual. (MARCUSCH, 2003).

Com o desenvolvimento de pesquisas bibliográficas, apresentação de seminários, experimentos, foi possível deixar os alunos aptos a compor um projeto com gêneros específicos, uma vez que souberam discernir entre elementos pré, pós e textuais e a formatação não só de um projeto, mas de outros trabalhos acadêmicos. (MEDEIROS, 2009). A inserção em pesquisas no início da vida acadêmica garante melhora no currículo e contribui para a continuidade dos estudos em programas de pós-graduação.

\section{Materiais e métodos}

Neste projeto, os sujeitos envolvidos foram estudantes do curso técnico de Agricultura, turma 1138 e FI 09 do I Período de Fruticultura Irrigada, e professores destas respectivas turmas do IF - Sertão Pernambucano, Campus zona rural. A comunidade contemplada foi formada por agricultores da terceira idade, ociosos ou trabalhadores que se encontravam no exercício de atribuições informais. $O$ local foi $o$ Assentamento Água Viva I, situado há menos de um quilômetro do referido Instituto - Zona Rural.

"Houve coleta e análise quantificada dos dados" (SANTOS, 2000) a partir da implantação de experimentos, uma horta comunitária no colégio Municipal do Assentamento, com as seguintes olerícolas: Acelga, Alface, Beterraba, Cenoura, cebolinha, Couve manteiga, Coentro, Pimenta Malagueta, Rúcula, Tomate cereja e outros que os assentados manifestar interesse em produzir para comercialização. Utilizou-se o método indutivo (BARROS, 2009) por meio do estudo de caso feito com os alunos da turma FI09 e 1138. Os mesmos desenvolveram projetos sobre olerícolas, culturas de ciclo curto. Os mini-projetos versaram sobre uma das culturas mencionadas e desenvolvidas em dupla. Os alunos do técnico fizeram somente pesquisas bibliográficas, "trabalho multidisciplinar que envolve informações das diversas habilidades que compõe a matriz curricular”. Piaget (2003), além disso, ajudaram na implantação do experimento.

Houve elaboração de projetos de implantação de horta orgânica comunitária, ao invés da convencional implantada comumente por outros alunos no Instituto. A escolha do local próximo a Instituição foi um dos critérios, 
Edilaine Pereira de Sousa et al.

uma vez que os Institutos devem desenvolver ensino, pesquisa e extensão. Além disso, a falta de informação, renda per capta baixa e interesse que esta comunidade manifesta quando a Instituição promove algum evento, isto é, comparece, participa de cursos de curta duração, etc. foi motivação a por em prática a pesquisa nesta localidade. As aulas sobre elaboração de projetos e pesquisas bibliográficas foram ministradas pelos professores de metodologia e a escrita feita entre quatro a oito semanas nas aulas de Português Instrumental. Na primeira semana, os estudantes escolheram a cultivar, fizeram pesquisas no laboratório de informática, sob a supervisão do professor desta área e na Biblioteca.

Em seguida, os alunos escreveram a Introdução e os Objetivos e entregaram em forma de rascunho, diversas vezes, para reescrituração. $\mathrm{O}$ mesmo processo ocorreu na semana seguinte com a elaboração de materiais e métodos, depois com o referencial teórico, cronograma, orçamento, resultados esperados e referências bibliográficas. A mesma metodologia foi aplicada com alunos do técnico, produziram seminários ou palestras, depois de feitas as pesquisas bibliográficas e apresentação aos assentados. Organizados o projeto e o seminário, aplicou-se um questionário semi-estrutrado com os discentes para identificar o nível de dificuldade em planejar de modo sistematizado de uma pesquisa. Em seguida, foram feitas apresentações em folhetos ou folders com os assentados, seguida de convite para as sete famílias que foram selecionadas por apresentar menor renda, identificadas por meio de entrevistas orais e visitas. Os agricultores receberam orientações de como implantar horta orgânica ao invés de convencional. Em seguida, fez-se a análise físico-química do solo e em uma área de $600 \mathrm{~m}^{2}$, implantaram 42 canteiros, divididos por piquetes, seis para cada assentado com insumos e equipamentos da Instituição.

Após o plantio, os assentados continuaram a receber orientações sobre o cultivo, manejo, produção e comercialização das hortaliças, inclusive houve previsão de receber capacitação sobre formas de processamento de pimenta, tomate, alho e outras olerícolas. Esse tipo de orientação ainda seria fornecido pelo setor de agroindústria do Instituto o qual demonstrará e incentivará o empreendedorismo a partir da elaboração de produtos, como molho de pimenta, pasta de alho, extrato de tomate, legumes em conserva e outros. E para embalagem, foram utilizados produtos recicláveis, como por exemplo: embalagens de vidro ou plástico (maionese, extrato, etc.).

\section{Resultados e discussão}

Com a produção de texto, utilizando-se a análise fatores de textualidade, percebeu-se um avanço considerável na escrita dos discentes. Um dos aspectos previsto foi o fator da situacionalidade. Percebeu-se que a produção tornou-se relevante para a situação comunicativa (KOCH, 2006). Estabeleceu-se a coesão e coerência a partir do entrelaçamento de elementos que compuseram o projeto e os quais subjacentes à superfície textual, mas entram em uma configuração veiculadora de sentidos.

No que tange à informatividade, foi inserida uma nova forma de se cultivar hortaliças em uma comunidade carente, repleta de indivíduos desprovidos de conhecimentos técnico-científicos. Para os discentes, foi uma nova maneira de se produzir textos, a partir de um contexto específico. Os alunos aprenderam a inserir citação direta e indireta no interior de alguns elementos como Introdução, materiais e métodos e, sobretudo no Referencial Teórico. Durante a pesquisa, os alunos organizaram referências de livros, artigos, periódicos. Com a reescrituração de textos, passaram a corrigir os desvios gramaticais, antes bem visíveis nas produções.

O trabalho em equipe foi significativo, pois a interação e cooperação de ambos aceleraram a elaboração da pesquisa e elevouse o nível de produção textual. As duplas aprenderam a fazer retextualização de gêneros, utilizando a intertextualidade sem plagiar o texto-fonte. A retextualização consiste em 
Edilaine Pereira de Sousa et al.

manter as ideias de um texto, mudar a forma ou estrutura de forma a estabelecer um diálogo com o autor. A relevância do tema propiciou aos estudantes aplicar os conhecimentos adquiridos em sala de aula. Eles perceberam a viabilidade da pesquisa, afirmaram ter aprendido muito. Apesar da dificuldade em redigir, sentem-se mais seguros.

Tabela I - Relevância da pesquisa científica

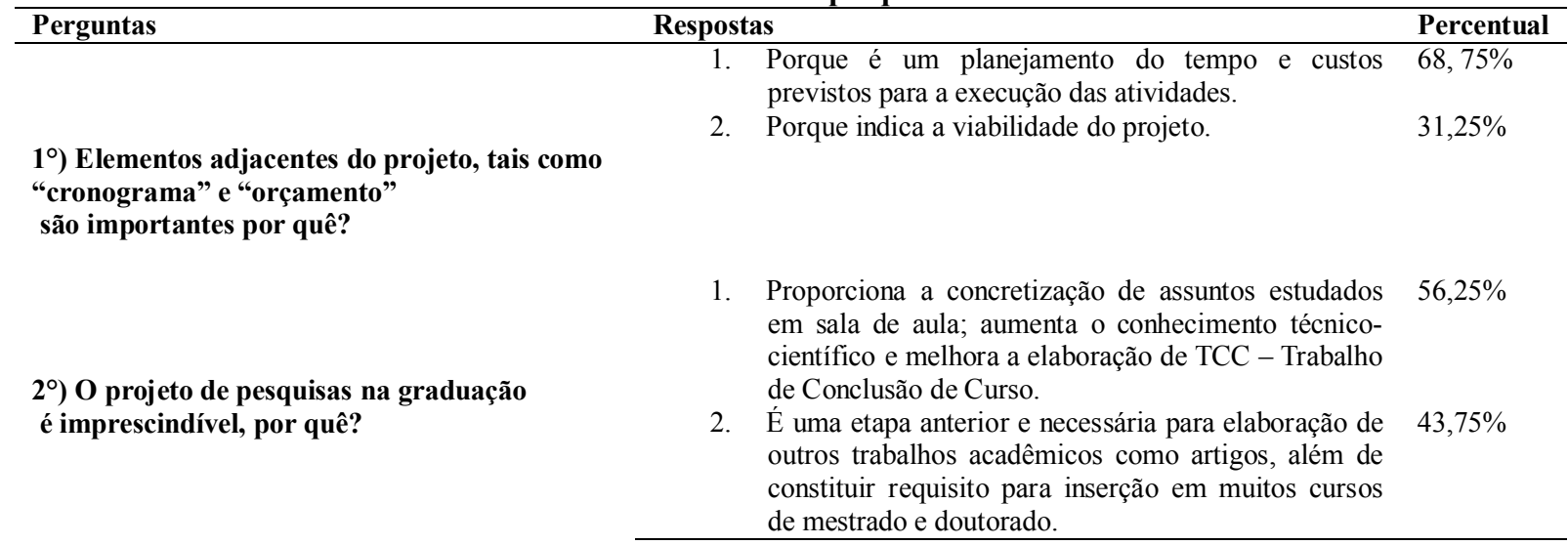

Metodologicamente, afirmam estar apto para compor um projeto, uma vez que sabem discernir entre elementos pré, pós e textuais e a formatação não só de um projeto, mas de outros trabalhos acadêmicos. Além disso, a revisão de gramática que estava prevista na ementa (pontuação, acentuação, regência, concordância e outros) foi vista de forma contextualizada conforme preconizam os PCNs (Parâmetros Curriculares Nacionais). A gramática aplicada ou funcional foi inserida em uma situação concreta de uso de algum gênero textual. A sistematização da gramatical não ocorreu de forma solta, aleatória, mas em uma situação específica de uso do gênero textual "projeto".

Esta pesquisa mostra que o ensino de gramática normativa no ensino básico $\mathrm{e}$ superior sem a prática de produção textual é vã. Ao iniciar o curso, alguns estudantes se comunicam utilizando variedades linguísticas informais, como por exemplo: regionalismos, gírias, etc. Isso deve ser discutido amplamente em sala de aula, sem preconceito. No entanto, é preciso salientar que a apropriação da linguagem padrão é imprescindível para comunicar-se e as Instituições de Ensino devem primar para que o repertório linguístico desses indivíduos amplie-se. Nesse contexto, aferiu-se o que se pretendia, pois o campo semântico na área de "agroecologia" foi amplamente discutido e por eles internalizado.

No questionário semiestruturado aplicado com os discentes, pode-se inferir que apesar da dificuldade em redigir, eles reconhecem a importância da elaboração de projetos na graduação como forma de aprimoramento da escrita, elevo intelectual e profissional. O questionário composto por dez questões a seguir, continha duas questões subjetivas, sintetizados na tabela 1 e oito, objetivas, vistas no gráfico a seguir. Totalizaram 34 alunos os quais responderam as perguntas em duplas. 
Edilaine Pereira de Sousa et al.

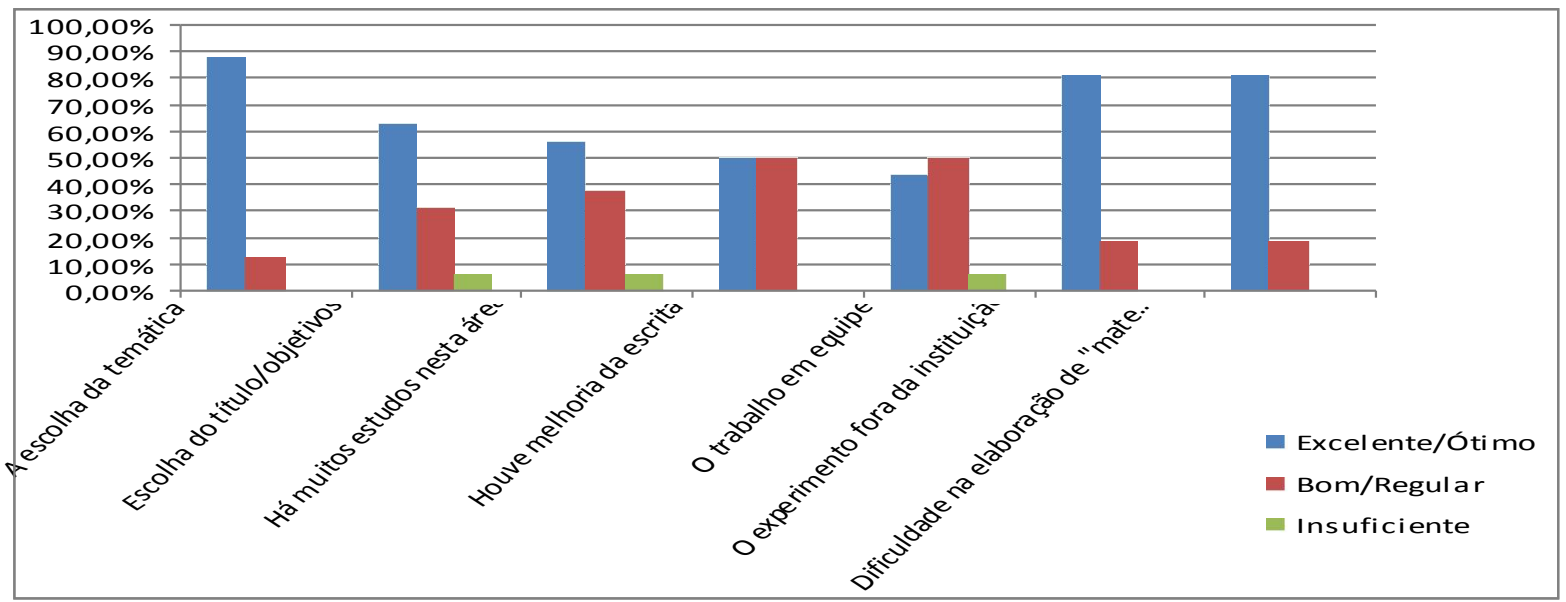

Figura 1. Avaliação dos discentes.

Com a implantação da horta orgânica comunitária no Colégio Municipal do assentamento Água Viva I, os estudantes e professores puderam compartilhar conhecimentos sobre técnicas de plantio de hortaliças, produção de compostos e aplicação em canteiros. As famílias participaram da produção de hortaliças adubadas com composto orgânico para geração de trabalho e renda, dentro dos princípios da Economia Solidária, ou seja: cooperação, solidariedade, auto-gestão e dimensão econômica.

Após a aquisição, limpeza da área, foi feito o preparo do solo que necessitou das seguintes atividades: subsolagem, gradagem.
$\mathrm{Na}$ marcação dos canteiros, utilizaram-se ferramentas, como enxada, barbante, piquetes, trema e mareta. Logo após, iniciou-se o levantamento dos canteiros, medindo $1.20 \times 10 \mathrm{~m}$ sendo que a distância entre um canteiro e outro é de $50 \mathrm{~cm}$ de distância para facilitar o manejo de irrigação e os tratos culturais. Feito o canteiro, deu-se inicio a adubação orgânica com esterco bovino cortido. As olerícolas foram semeadas após a adubação com $151 / \mathrm{m}^{2}$ de esterco de bovino e coberto com palha de coco para proteção ao germinar. As mudas foram transplantadas no espaçamento de $0.20 \mathrm{mx} 0.20 \mathrm{~m}$ aos 28 dias após o semeio (Figura 2).

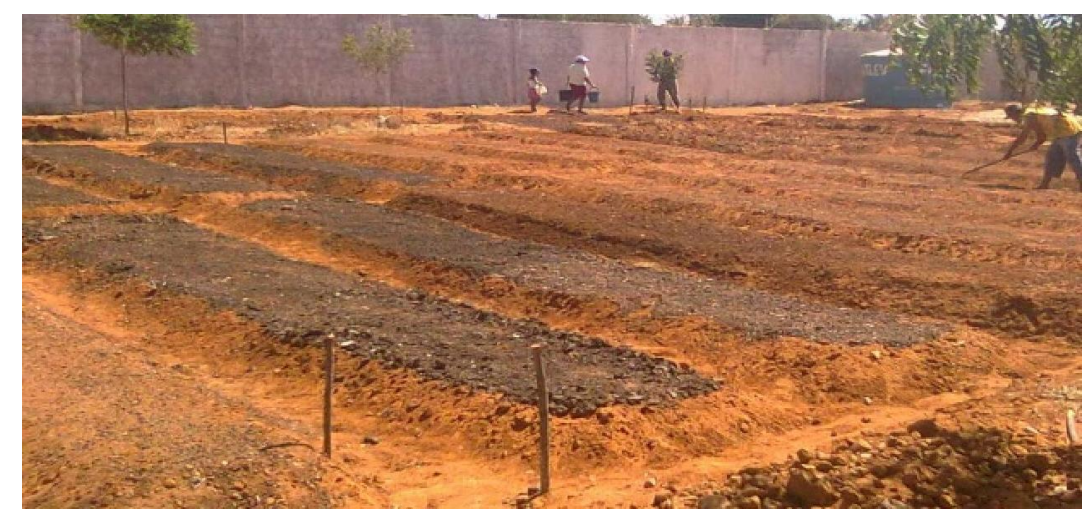

Figura 2. Adubação orgânica e irrigação manual

O sistema de irrigação instalado foi com uma caixa d'água de $7 \mathrm{mil}$ litros. Isso beneficiou as famílias diretamente ligadas à horta orgânica. A Instituição disponibilizou regadores para as famílias. Em visita a outras hortas, em que o Instituto presta assistência, detectou-se que a maioria das famílias tem apenas uma única fonte de renda destas atividades. Em entrevista, os horticultores afirmaram sustentar-se inteiramente da horta.

Para o controle de pragas e doenças foi realizado o monitoramento periódico com 
Edilaine Pereira de Sousa et al.

intuito de minimizar a infestação provocada por doenças, pragas e insetos. Aplicou-se calda sulfocálcica e biofertilizante. Dessa forma, não houve utilização de adubo químico para que houvesse um melhor aspecto visual e qualidade do produto perante o consumidor.

Das sementes implantadas, germinaram $100 \%$, conforme a figura 3 abaixo. Algumas hortaliças já estão boas para comercialização (figura 4). Foram colhidas as culturas que apresentarem qualidade, coloração adequada para que pudessem chegar ao mercado consumidor em bom estado de conservação e maturação. A seleção atenderá às exigências do mercado. As que não apresentarem condições suficientes para comercialização in natura foram enviadas ao Instituto para processamento no setor de agroindústria e elaboração de pasta de alho, extrato de tomate, molho de pimenta e legumes em conserva prevista nos materiais e métodos.

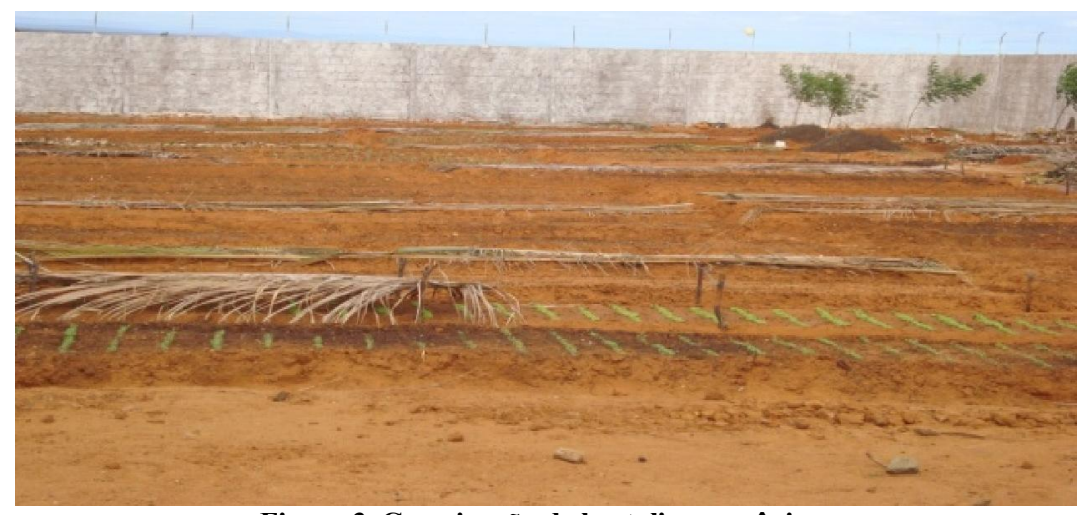

Figura 3. Germinação de hortaliças orgânicas
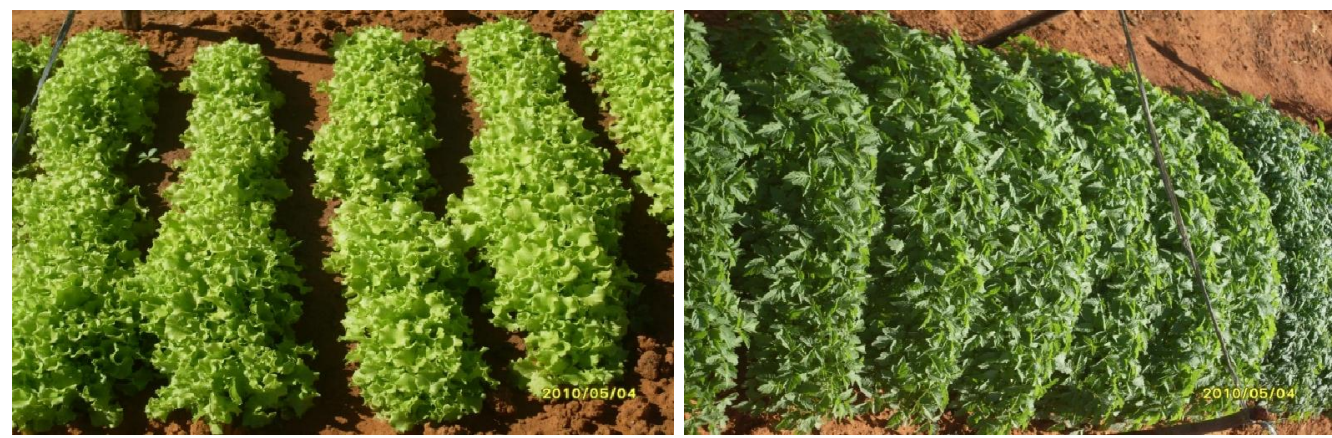

Figura 4. Hortaliças prontas para comercialização

\section{Considerações finais}

Por meio da orientação, espera-se que os discentes continuem a escrever de modo proficiente e possam dar continuidade aos trabalhos, ajudando os assentados a produzir na horta e desenvolver o processamento de algumas destas culturas no setor de agroindústria do Instituto e assim, obterão renda sem agredir ao meio ambiente, isto é, gerar renda de modo sustentável.

\section{Referências bibliográficas}

ANDRADE, M. C. O. Atlas escolar de Pernambuco. João Pessoa: GRAFSET, 2003.

BARCIOTTE, Maria Lucia. A importância da educação para o consumo responsável. $\mathrm{RJ}$ : Nova Fronteira, 2002.

BARRos, J. D. O Projeto de Pesquisa em História. 5. ed. Petrópolis, RJ: Vozes, 2009. 
Edilaine Pereira de Sousa et al.

CERVEIRA, R. Perfil de consumidores de produtos orgânicos. Disponível em: www.megaagro.com.br/organica.

COSTABEBER. J. A. Agroecologia: Processo de transição no RS, Brasil. RS: UVG, 2000.

DELL'ISOLA, Regina Lúcia Péret. Retextualização de gêneros escritos. RJ: Lucerna, 2007.

ESPINDOLA, J. A. A.; et AL. Adubação verde para hortaliças. In: CONGRESSO BRASILEIRO DE OLERICULTURA, 46, Resumos..., Goiânia, GO. 2006, p.3535.

FAZENDA, Ivani Catarina, A. Interdisciplinaridade um projeto em parceria. $-5^{\circ} \mathrm{Ed}$. SP: Loyola, 2002.

FEUERSTEIN, Reuven. Aprendizagem mediada dentro e fora da sala de aula. Tradução José Francisco de Azevedo - $3^{\mathrm{a}} \mathrm{Ed}$, SP: Instituto Pieron de Psicologia aplicada, 2002.

FILGUEIRA, F. A. R. Novo Manual de Olericultura: agrotecnologia moderna na produção e comercialização de hortaliças. 3 . Ed. Viçosa, MG: UFV, 2007.

FRANCE, L. D. A inovação como estratégia de diferenciação na agricultura. Disponível em: www.sielo.com.br.

GUIMARÃES, Mauro. A dimensão Ambiental na Educação. 8. ed. SP: Papirus, 2007.

$\mathrm{KOCH}$, Ingedore G.Villaça. Introdução a Linguística textual. 2. ed. SP: Martins, Fontes, 2006.

construção de sentidos - 9 . Ed, SP: Contexto, 2008.

MACEDO, Neusa Dias. Iniciação a Pesquisa

Cientifica. 3. Ed. São Paulo: Loyola, 1995.
MARTINS, Jorge Santos. O trabalho com projetos de pesquisa. $5^{\mathrm{a}} \mathrm{Ed}:$ Campinas, SP, Papirus, 2001.

MEDEIROS, João Bosco. Português Instrumental. 8. Ed. São Paulo: atlas, 2009.

OLIVEIRA, E. Q. et al. Cultivo consorciado com hortaliças. Horticultura Brasileira. Brasília, v. 22, n. 2, 2004.

PELICIONI, M. C. F. Educação em saúde e educação ambiental estratégias de construção da escola promotora da saúde. Livre-Docência. Universidade de São Paulo, Faculdade de Saúde Pública, 2000.

PIAGET, Jean. Psicologia e pedagogia. Rio de Janeiro: Forense Universitária, 2003.

RAMOS E. L. A Reforma como paradigma: um Estudo de caso na EAF-RioVerde. Dissertação de Mestrado.

ROJO, Roxante et al. A prática de linguagem em sala de aula - praticando os PCNs. SP: EDUC/PUC-SP, 2000, P.27-38.

SOARES, M. Letramento: um tema em três gêneros. 3 ed. Belo Horizonte: Autêntica, 2000 .

SOUZA, Jacimar Luis de.; REZENDE, Patrícia Lacerda. Manual de Horticultura Orgânica. Viçosa: 2003a. 564 p.

SOUZA, Nali de Jesus de. Desenvolvimento Econômico. $5^{\circ}$ ed.. São Paulo: Atlas, 2005.

XAVIER, F. A. da Silva; MAIA, S. M. Ferreira; OLIVEIRA, T. Senna de; MENDONÇA, E. de Sá. Biomassa microbiana e matéria orgânica leve em solos sob sistema agrícola orgânico e convencional. CE: Revista Brasileira de Ciência do Solo, v.30, n.2. p. 247-258, 2006. 